\title{
intuitio
}

Revista do PPG em Filosofia da PUCRS

http://dx.doi.org/10.15448/1983-4012.2019.1.32528

\section{ENSAIO ENTRE EPISTEMOLOGIA ANALITTICA E HERMENÊUTICA FILOSÓFICA}

\author{
ESSAY BETWEEN ANALYTICAL EPISTEMOLOGY AND \\ PHILOSOPHICAL HERMENEUTICS
}

Cristian Marques ${ }^{1}$

Resumo: O presente ensaio visa explorar uma aproximação do coerentismo epistemológico, na teoria apresentada por Keith Lehrer, com a filosofia hermenêutica, principalmente nas formulações feitas por Martin Heidegger em Ser e Tempo. Tal aproximação, embora inusitada e para alguns suspeita, foi apontada como um possível caminho, por Johnatan Dancy e Merold Westphal, para solucionar impasses na epistemologia que remontam às suas primeiras formulações e acompanham a epistemologia contemporânea. Na primeira seção, discutimos o estranhamento dessa aproximação para, na segunda seção, resgatar os pontos centrais da história da epistemologia até a indicação de Westphal de tratar a hermenêutica heideggeriana como fundamento para uma epistemologia coerentista. Na seção três, apresentamos a teoria coerentista de Lehrer. Na última seção, resgatamos as compreensões centrais de Heidegger acerca do conhecimento e esboçamos, à guisa de conclusão, que cuidados o epistemólogo deveria ter se assumir uma posição hermenêutica.

Palavras-chave: Coerentismo. Epistemologia. Hermenêutica. Heidegger.

Abstract: The present essay aims at exploring an approximation of epistemological coherentism, in Keith Lehrer's theory with hermeneutic philosophy, especially in

\footnotetext{
1 Pontifícia Universidade Católica do Rio Grande do Sul - PUCRS. ORCID: http://orcid.org/0000$\underline{0002-7743-8356}$
} 
the formulations made by Martin Heidegger in Being and Time. Such an approach, although unusual and suspicious for someone, was pointed out as a possible path by Johnatan Dancy and Merold Westphal, to solve impasses in epistemology that go back to its first formulations and accompany contemporary epistemology. In the first section, we discuss the strangeness of this approach. In the second section, we retrieved the central points of the history of epistemology up to Westphal's suggestion of treating Heideggerian hermeneutics as the basis for a coherentist epistemology. In section three, we present Lehrer's coherentist theory. In the last section, by way of conclusion, we retrieve Heidegger's central understandings of knowledge and outline, what caveats should the epistemologist take to assume a hermeneutical position.

Keywords: Coerentism. Epistemology. Hermeneutics. Heidegger.

\section{I - Preliminares e esclarecimentos acerca da presente aproximação}

É preciso começar com alguns esclarecimentos fundamentais e decisivos acerca do tema e problemática aos quais o título aponta. Expor brevemente como encaramos o tema parece-nos relevante a fim de mitigarmos uma aproximação inicial desfavorável por nosso uso de certos termos e expressões. Para os leitores assíduos na obra de Martin Heidegger e Hans-Georg Gadamer, aproximar hoje o termo "epistemologia" do termo "hermenêutica" requer alguma explicação mostrando, o mais claro possível, do que se trata exatamente. Isso se deve por diversos motivos; mas, pelo menos, os que seguem abaixo acreditamos serem as mais fortes razões para o dissenso.

A questão talvez mais candente, por possuir uma abundante polissemia, diz respeito ao uso do termo "epistemologia". No âmbito de grande parte da filosofia contemporânea, ele assume contornos bem definidos como teoria do conhecimento. $\mathrm{O}$ estudo que grosso modo visa revelar de que maneira e em que circunstâncias podemos afirmar ter conhecimento. Em outras palavras, as condições de possibilidade para assegurar a afirmação de posse de conhecimento. Afirmar ter conhecimento, nesse 
contexto, é fazer uma distinção que remonta, em certo sentido², aos diálogos platônicos ${ }^{3}$. É afirmar que se possui algo diferente - e melhor - que doxa, a simples opinião; que se possui episteme, conhecimento - um tipo especial de crença verdadeira que não se esvai contra a mínima indagação por razões que a justifiquem. Quando se tem presente essa noção para o termo "epistemologia", fica clara a distância com a posição filosófica conquistada por Heidegger e seu epígono Gadamer.

Também podemos apontar outro uso igualmente frequente em torno do termo "epistemologia", qual seja, o de filosofia da ciência 4 . Essa noção pode causar menos estranhamento, ao leitor de Heidegger e Gadamer, quando aproximada com a hermenêutica filosófica, embora ela não seja menos problemática que a noção analítica de epistemologia. O estranhamento pode ser menor porque se encontram, em ambas as obras dos filósofos referidos, textos que abordam questões relativas às ciências, principalmente as chamadas humanas. Todavia, nenhum deles visou tematizar principalmente problemas de filosofia da ciência. Isso é claro no que tange a Heidegger, nem tanto em relação a Gadamer. Podese encontrar sem muita dificuldade leituras da obra de Gadamer que o aproximam de concepções preocupadas com a legitimidade das ciências humanas, enquanto ciências, frente às ciências naturais. Entretanto, sabemos que a presença das ciências do espírito, na segunda parte de Verdade e Método ${ }^{5}$, visa um alcance maior que os problemas de metodologia das ciências humanas (a despeito das leituras que tomam Verdade e Método por um libelo do uso de métodos nas ciências humanas).

\footnotetext{
2 Do ponto de vista do rigor histórico e filosófico, Platão não fez propriamente teoria do conhecimento, algo como tal surgiu somente - esse é um consenso na Filosofia - no período moderno com os embates entre racionalistas e empiristas. Todavia, esse resumo histórico da visão epistemológica não diz respeito necessariamente a como Platão via o tema do conhecimento, mas que o tema do conhecimento não estava ausente em seus trabalhos.

3 Penso aqui mais diretamente nos diálogos Menon e Teeteto, mas também em certas passagens da República.

4 Temos em mente aqui autores que seguiram o uso feito por Gaston Bachelard, como Karl Popper e Thomas Kuhn, entre outros.

5 GADAMER, Hans-Georg. Verdade e método. 12. ed. Petrópolis: Vozes, 2012.
} 
Sem dúvida, ao lermos Heidegger e Gadamer, auxiliados também por seus comentadores mais experimentados, percebemos que suas tematizações movimentam-se em um âmbito diferente daquele em que se situa a epistemologia, como acima esboçamos ${ }^{6}$. Ambos os autores estavam muito mais preocupados em tematizar questões ontológicas; e o desfile de outros temas em suas obras - como a técnica, método, arte e ciências humanas (para citar só alguns) - antes de limitar suas propostas, serviram como uma maneira de explicitação do alcance e amplitude de suas conquistas filosóficas. Assim, temos presente que o uso do termo "epistemologia" encontra-se majoritariamente inscrito em uma tradição metafísica (para falar com Heidegger), da qual o filósofo é profundo crítico.

Todavia, não é necessário que tomemos por "epistemologia" somente os usos mais frequentes ou que consideremos irreconciliáveis as duas posições? se tomadas certas precauções. Heidegger mesmo, de certo modo, retirou do contexto das discussões epistemológicas neokantianas a pergunta pelo sentido do ser e, embora ele não tenha insistido em um projeto epistemológico, tratou de desenvolver aquele espaço no qual é possível a atividade de conhecimento ${ }^{8}$. Entretanto, por que fazer uso de um termo disputado se nosso interesse é perseguir intuições de uma posição distanciada e crítica daquele uso majoritário do termo "epistemologia"? A motivação é manter próximas as questões de fundo que esse termo também suscita: $O$ que é conhecimento? Que critérios contam para afirmarmos ter conhecimento? É necessário diferenciar conhecimento de outros tipos de conteúdos mentais ou crenças? Essas perguntas já não restringem de modo decisivo

\footnotetext{
6 Essa maneira de definir epistemologia é considerada pela tradição como um tipo de conhecimento, o chamado proposicional, considerado o principal foco da atual epistemologia. Cientes de que a tradição epistemológica contemporânea distingue o conhecimento em diferentes tipos, talvez um tipo seja passível de aproximação com as posições heideggerianas e gadamerianas melhor que outros.

7 Não seguimos aqui o uso que faz Richard Rorty da oposição mutuamente excludente entre epistemologia e hermenêutica.

8 STEIN, Ernildo. Pensar é pensar a diferença: filosofia e conhecimento empírico. 2. ed. ljuí: Unijuí, 2006, p. 87-91.
} 
a questão do conhecimento? De que modo podemos melhor abordar e levantar questões quando se tematiza o conhecimento? Essas e muitas outras questões compõem o bojo do termo "epistemologia".

Esses breves apontamentos introdutórios são elementos para se ter em mente ao ver tentativas de aproximar a hermenêutica filosófica da epistemologia. O presente ensaio não pretende resolver os problemas dessa aproximação, nem testar se ela é possível; mas, isso sim, apontar pontos de aproximação que reforçam a ideia de que uma epistemologia a partir da hermenêutica filosófica é um empreendimento possível. Pode-se dizer do presente ensaio que está inscrito em um horizonte mais amplo de pesquisa traduzido como uma tentativa de investigar a possibilidade e a plausibilidade de uma teoria do conhecimento que leve em consideração as conquistas alcançadas tanto por Heidegger e Gadamer quanto pelo movimento fenomenológico como um todo. O que há de epistemológico em um sentido que visa encontrar, no espaço aberto pela hermenêutica chamada de filosófica, um lugar onde se possa estabelecer uma teoria do conhecimento já não no sentido clássico da filosofia moderna.

Uma empreitada dessa natureza parece estar impedida já de partida em Heidegger. Seria um esforço contraproducente formular uma teoria do conhecimento a partir da inteligibilidade e da sensibilidade dentro do quadro teórico de Heidegger; porque, justamente, partir desses pontos leva a aporias, como a impossibilidade de resolver como se dá o acesso ao mundo pelo sujeito cognoscente. Com Heidegger, essa questão é dissolvida explicitando que a problemática de uma teoria do conhecimento é um processo posterior, derivado de uma pré-compreensão que se "constitui na relação entre o Dasein e os objetos do seu mundo, o mundo da cultura"9. Com isso, poderíamos talvez pensar que o sentido de uma teoria do conhecimento estaria esvaziado por já, desde sempre, estarmos em um

9 STEIN, Ernildo. Racionalidade e existência: o ambiente hermenêutico e as ciências humanas. 2. ed. Ijuí: Unijuí, 2008, p. 109. 
mundo prático no qual tanto nos compreendemos como nos explicitamos ${ }^{10}$. Ou seja, já temos conhecimento de qualquer maneira. Qual o interesse então em uma teoria do conhecimento? Todavia, o tratamento dado por Heidegger não substitui a questão do conhecimento, mas possibilita que a recoloque em outro âmbito e parâmetros, eliminando o esquema sujeito-objeto. Ele não desenvolve uma teoria do conhecimento sobre os resultados de suas conquistas filosóficas, mas mostra o âmbito em que o conhecimento pode se dar ${ }^{11}$.

\section{II - Percurso da epistemologia à hermenêutica}

Desde muito cedo, a filosofia pergunta-se sobre o fenômeno do conhecimento. A epistemologia12 é tão antiga quanto os outros ramos filosóficos. Podemos perceber como o conhecimento auxilia-nos tanto a lidar com o mundo quanto a entendermos a nós próprios como um ser singular na natureza. Compreendemos que conhecer algo já está estreitamente ligado a nossa relação com o mundo ${ }^{13} \mathrm{e}$, quanto mais passamos a refletir sobre essa relação e em como se dá nosso conhecimento, passamos a questionar a correção, a validade e até a possibilidade de conhecermos seja o que for.

10 STEIN, Ernildo. Pensar é pensar a diferença: filosofia e conhecimento empírico. 2. ed. Ijuí: Unijuí, 2006, p. 91.

1 STEIN, Ernildo. Pensar é pensar a diferença: filosofia e conhecimento empírico. 2. ed. Ijuí: Unijuí, 2006, p. 92.

12 Importante sublinhar que o uso aqui da palavra 'epistemologia' está estreitamente ligada ao uso que é feito por epistemólogos majoritariamente associados ao que se convencionou vagamente chamar de vertente analítica, tradição analítica ou modo analítico de proceder.

13 Essa maneira de expor a relação humano-mundo é tipicamente heideggeriana e revela o posicionamento fenomenológico do qual ele parte. Heidegger, em vistas de superar o abismo da dualidade sujeito-objeto, presente sobretudo na filosofia moderna, defendeu extensamente em Ser e Tempo a necessidade de partirmos da noção de ser-no-mundo e não da noção de sujeito (que levaria inevitavelmente a paradoxos). Desde antes de Ser e Tempo, Heidegger, já trabalhava em questões convergentes a essa. Em sua obra Ontologia: Hermenêutica da faticidade, de 1923, lança as bases do que será tratado principalmente em Ser e Tempo, a saber, que a compreensão (Verstehen) não é meramente um processo cognitivo, mas um existencial - conjuntamente ao sentimento de situação ou sintonia (Befindlichkeit) e ao discurso (Rede) - constitutivo e cooriginário da abertura de nosso ser ao mundo. Por isso, em Heidegger, temos que a compreensão é um já sempre compreender mundo. 
Nos diálogos Menon (97e-98a) e Teeteto (202c) ${ }^{14}$, de Platão, há uma busca pelo que diferencia a crença (doxa) do conhecimento (episteme). Platão já havia percebido ${ }^{15}$ o risco de um regressus e tentou salvar a justificação pressupondo (de maneira um tanto dogmática) uma espécie de acesso imediato, uma apreensão de um princípio primeiro, e não hipotético, com o real e uma conformidade dessa ideia do real com o aparecer do fenômeno. Aristóteles também foi intrigado pelo tema oferecendo com seu nous, igualmente arbitrário, um acesso fundacional ao conhecimento.

A exigência de certeza como garantia de conhecimento passou a ser um elemento relevante na modernidade, levando a posições como a de Descartes. O procedimento cético cartesiano exige uma certeza onde não há espaço para dúvidas em qualquer grau. Nenhuma razão pode fornecer uma justificativa que satisfaça tal exigência, já que, ao pôr o ato de duvidar como o ponto primordial, este mesmo não é uma razão, mas um acesso imediato (arbitrário - poderia ser outro tipo de acesso imediato) a um conhecimento. Para termos "conhecimento" nessa filosofia, é preciso que haja uma mediação através da razão entre a crença verdadeira e o mundo. Desse modo, não se consegue escapar do problema da justificação exatamente porque a ninguém é dado um "salvo conduto" que lhe exima de dar razões para crer. Decorre que se temos de dar razões para crer que $p$, e não parece haver nenhum ponto de parada natural no ato de dar razões (S sabe que $p$, porque $r$, e $r$ é boa razão para crer em $p$ porque $s$, e $s$ justifica $r$ porque $t$ e ad infinitum...). Por conta do regresso das justificativas ad infinitum, não é possível justificar racionalmente que ' $S$ sabe que $p$ '; portanto, não há conhecimento. Mas, se aceitarmos o apelo cético assim como apresentado, então teremos que repensar qual o papel da investigação epistemológica neste ponto: conhecimento terá de ser somente como um fim sempre buscado, desejado. Ora, se é somente um fim a que se busca o qual não se pode atingir, então a epistemologia

\footnotetext{
14 "opinião verdadeira acompanhada de razão".

15 ROSS, David. Teoría de las ideas de Platón. 5. ed. Madrid: Catedra, 2001.
} 
pareceria um empreendimento enganoso ou mera perda de tempo. $\mathrm{O}$ cético dirá que é exatamente isso que está tentando dizer para nós. Essa é uma posição inaceitável, principalmente porque é somente através de um modo específico de filosofar que se chega a esta dúvida extremada.

O ceticismo cartesiano é contra intuitivo, porque é tão rigoroso que retira o caráter de "conhecimento" de asserções simples. Asserções que não oferecem problemas à nossa intuição em atribuir conhecimento, tornando bizarra a negação de ' $S$ sabe que $p$ ' em certos casos. Por exemplo, posso dizer sem problemas no cotidiano que "sei que sou gaúcho" sem esperar que seja assaltado pelo cético acerca de justificativas que assegurem que esta asserção não passe de mera crença verdadeira. Mesmo que eu seja questionado como sei que sou gaúcho, posso oferecer razões prontamente acessíveis a esta asserção ao limite de tornar a conversa bizarra. Por exemplo: Como sei que sou gaúcho? Porque nasci no Rio Grande do Sul e quem nasce lá é chamado de gaúcho. Como sei que nasci no Rio Grande do Sul? Porque tenho uma certidão de nascimento que atesta isso. Como sei que a certidão não está errada, que o tabelião não se equivocou na hora de datilografar a certidão? Porque, além do tabelião, tenho testemunhas (os pais), e assim por diante. Entretanto, o cético não é inteiramente afastado porque também parece perfeitamente razoável perguntar com que razão posso dizer que "sei que vejo um husky"16 se recém chego ao Alasca e, estando o animal a certa distância, não há nenhuma característica ou circunstância que o distinga dos lobos da região? Exemplos como esse, e outros, são fartos na literatura e levam a crer que o uso metodológico do cético cumpre uma função para o epistemólogo de verificador dos limites de uma teoria epistemológica ${ }^{17}$.

Outras manobras fundacionistas importantes foram tentadas na tradição filosófica, como a postulação de um a priori (Kant), intuição in-

\footnotetext{
16 SOSA, Ernildo. Epistemology: an anthology. Malden: Blackwell Publishers, 2000.

17 BONJOUR, Laurence. The structure of empirical knowledge. Cambridge: Harvard University Press, 1985, 14-15.
} 
telectual (Fichte, Schelling), ou a tentativa avant la lettre coerentista ${ }^{18}$ de uma prova no final do sistema exatamente da necessidade das categorias assumidas no início do sistema (Hegel). Mas, de fato, essas estratégias fundacionistas não resistiram ao assalto cético que apontava o caráter arbitrário de onde se partia a argumentação racional da justificação do conhecimento. Toda teoria do conhecimento até esse momento parece necessitar de alguma justificação externa a ela mesma ou que consiga mostrar como é causa de si. O empreendimento epistemológico foi em larga medida guiado pela ideia de que conhecimento é crença verdadeira justificada. Mais tarde, tal ideia foi posta à prova por Edmund Gettier ${ }^{19}$, sofisticando o que se entende por conhecimento. Se antes a noção de justificação dava uma relação sólida e suficiente para garantir a conexão entre razão e a verdade necessária, agora é preciso que uma teoria do conhecimento diga o que conta como justificação, além de dizer o que é justificação. De toda forma, parece que, para um sujeito ' $S$ ' dar justificação de que sua crença é o caso, é preciso que ' $S$ ' tenha acesso a essa justificativa, do que não faria sentido dizer que: $S$ sabe que $p$, mas não pode justificar agora; pois, a justificativa ainda será descoberta, ou não se lembra, ou perdeu a evidência que justificava, etc.

$\mathrm{Na}$ contemporaneidade, boa parte dos esforços em epistemologia está em teorias da justificação. Busca-se uma justificação para o conhecimento legítimo ou, dito de outro modo, o que é que epistemiza a crença verdadeira, recusando-se postulados ad hoc ${ }^{20}$. Uma teoria da justificação contemporânea que seja robusta deve não só epistemizar a crença verdadeira, mas deve ela mesma submeter-se ao seu princípio regulador (justificação da justificação?) e sair incólume. Assim, com Alstonn ${ }^{21}$, para

\footnotetext{
18 Esses termos (fundacionismo e coerentismo) nunca foram usados antes de meados do século $X X$, mas uso eles aqui de modo anacrônico para melhor explicitar a argumentação.

19 GETTIER, E. Is justified true belief knowledge? Analysis, [s. l.], n. 23, p. 121-123, 1963.

20 AUDI, Robert. The structure of justification. Cambridge: Cambridge Univ., 1993, p.14.

${ }^{21}$ ALSTON, William. P. Epistemic justification: essays in the theory of knowledge. Ithaca: Cornell University Press, 1989, 1989. p.185.
} 
conferir justificação a ' $p$ ', em 'S sabe que $p$ ', é preciso que aquilo que justifica a crença esteja dentro da "perspectiva" ou do "ponto de vista" de 'S' e seja acessível a 'S' de modo especial. Significa que a justificação deve ser diretamente acessível ou ainda infalivelmente acessível. Mesmo agora não estamos livres do assalto cético: como sei que esse acesso é infalível ou diretamente conectado com a verdade? Parece que qualquer resposta rápida nos faz cair no problema do regresso infinito epistêmico.

Alguns epistemólogos, como Peter Kleinn ${ }^{22}$, muito recentemente têm defendido que o regressus talvez não precise ser estancado, mas transformado de um "malum infinitum" para um "bonum infinitum". É a posição chamada de infinitismo, "teoria epistêmica segundo a qual as razões que justificam uma opinião devem ser infinitas em número e não-repetidas"23. Todavia, essa posição ainda está sendo avaliada e possui muitas controvérsias, embora pareça resolver melhor alguns problemas de outras teorias ${ }^{24} 25$. Outro tipo de resposta que pode ser dada ao problema do regressus, conforme Audi ${ }^{26}$, é que a “justificação de uma crença emerge de sua coerência com outras crenças aceitas por um sujeito epistêmico". Em outros termos, o problema do regresso é sanado apelando para a noção de "mútuo suporte" 27 entre crenças. Esse tipo de resposta é chamado de coerentista. Outra forma de responder ao problema (e tem sido a principal estratégia filosófica, como mostramos desde o início dessa seção do ensaio) é dizer que algumas crenças teriam

\footnotetext{
22 KLEIN, Peter D. Infinitism's take on justification, knowledge, certainty and skepticism. Veritas, Porto Alegre, v. 50, n. 4, p. 153-172, 2005.

23 FLORES, Tito Alencar. Epistemic levels, the problem of easy knowledge and skepticism. Veritas, Porto Alegre, v. 54, n. 2, p. 109-129, 2009.

24 FLORES, Tito Alencar. Racionalidade epistêmica e o processo de justificação. 2004. Tese (Doutorado em Filosofia) - Faculdade de Filosofia e Ciências Humanas, Pontifícia Universidade Católica do Rio Grande do Sul, Porto Alegre, 2004.

25 FLORES, Tito Alencar. The problem of the criterion, knowing that one knows and infinitism. Veritas, Porto Alegre, v. 50, n. 4, p. 109-128, 2005.

26 AUDI, Robert. Belief, justification and knowledge. California: Wadsworth, 1988, p.83.

27 BONJOUR, Laurence. The structure of empirical knowledge. Cambridge: Harvard University Press, 1985.
} 
um status especial, no qual uma justificação não seria necessária para elas e, em última instância, todas as justificações remeteriam a elas. Essa posição é chamada de fundacionismo ${ }^{28}$.

Alvin Goldmann ${ }^{29}$, entre outros ${ }^{30}$, ofereceu uma crítica persistente a estas posições, que pode ser resumida assim: Se, de algum modo, a justificação deve ser definida em função da verdade, parece que nenhuma das posições conseguiu uma definição de conhecimento que conectasse de modo satisfatório 'justificação' com 'verdade', mantendo um abismo entre sujeito cognoscente e aquilo que é conhecido; falta identificar o processo conducente à verdade (truth-conducive), o que liga a justificação com a verdade. Todavia, também não é fácil saber o que seja esse processo conducente à verdade: será que poderíamos dizer que é um "ver"? Se sim, então teríamos que definir as condições que devem ser satisfeitas para que um observador 'S' possa "ver" aquilo que justifica sua crença em ' $p$ '. Notamos que há boas intuições para todas as posições, assim como para suas críticas - é o que mantém a discussão em voga. Seja qual for o argumento apresentado, já sabemos ao menos que ele deve sobreviver a contraexemplos e não estar gettierizado ${ }^{31}$, embora não saibamos ainda qual é a justificativa válida, ou o que pode ser um justificador para ' $\mathrm{S}$ sabe que $p$ ', que resista a isso.

Entretanto, ainda assim, parece que o tipo de resposta que dermos a pergunta "o que é conhecimento?" determinará o que pode ou não pode justificar uma crença verdadeira para que consideremos conhecimento. Acaso o que dá significado ao termo 'conhecimento' é sua ligação com o tipo de justificação que se dá a uma doxa para ser tomada como episteme? Parece que sim, vejamos: Se dissermos que "conhecimento é uma crença

\footnotetext{
28 POLLOCK, John L.; CRUZ, Joseph. Contemporary theories of knowledge. 2nd ed. Lanham: Rowman \& Littlefield, 1999, p. 30.

29 GOLDMAN, A. What is justified beilief? In: PAPPAS, G. (Ed.). Justification and knowledge: new studies in epistemology. Dordrecht: D. Reidel, 1979. p. 1-24.

30 AUDI, Robert. The structure of justification. Cambridge: Cambridge Univ., 1993, p. 299-303.

${ }^{31}$ Esse neologismo é frequentemente usado por epistemólogos analíticos e significa simplesmente que certa tese epistemológica deve sobreviver aos contraexemplos de Gettier à análise clássica do conhecimento.
} 
baseada em uma ligação confiável com a verdade", nosso significado de conhecimento será diferente daquele que diz que "conhecimento é toda crença que pode ser estabelecida como verdadeira dentro de uma rede semântica coerente". Esse empreendimento da epistemologia de buscar uma justificação robusta não soa tanto pretensioso como surpreendente: como sabemos, ou melhor, que boas razões temos para crer que essa tarefa é possível? O que temos é certa intuição (herdada é claro do projeto platônico) de que parece realmente haver, pelo menos, uma diferença entre a simples opinião (crença de que $p$ ) e o saber (conhecimento de que p): aquele que sabe, sabe por que tem acesso disponível a boas razões, ou a garantias, ou a condições de rastreabilidade que justifiquem sua crença. Construir uma teoria do conhecimento válida, nesses moldes e levando em conta o cético de modo metodologicamente orientado, tem sido em grande parte o empreendimento contemporâneo na epistemologia.

De que modo devemos estruturar nosso sistema de crenças para que tenhamos crenças as quais possamos chamar de conhecimento? Podemos notar que, em relação ao conhecimento, não há unanimidade quanto à sua possibilidade, fontes, justificação ou essência ${ }^{32}$. O que temos hoje à disposição são diversas teorias que se sucedem e se apresentam como explicação ao fenômeno do conhecimento. As dificuldades e problemas da epistemologia, muito sucintamente expostos acima em um apanhado histórico impressionista, levaram alguns epistemólogos a procurar possibilidades de solução em outras abordagens. Jonathan Dancy ${ }^{33}$, um conhecido epistemólogo, quando se perguntou pela (im)possibilidade da epistemologia nos parâmetros dados pela filosofia de tradição analítica, apontou à proposta de Hegel como uma tentativa de superação do problema da diferença entre o conhecimento

\footnotetext{
32 FOLEY, R. Conceptual diversity in epistemology. In: MOSER, Paul K. (Ed.). The Oxford handbook of epistemology. Oxford: Oxford University Press, 2002. p. 177-203.

33 DANCY, Jonathan. Introducción a la epistemología contemporánea. 2. ed. Madrid: Tecnos, 2007, p.258-274.
} 
para nós e o conhecimento em sí34. Já o epistemólogo Merold Westpha|35 afirmou peremptoriamente que "hermenêutica [filosófica] é a epistemologia". Apontava ele para a possibilidade (não desenvolvida ainda, inclusive por ele mesmo) de que a interpretação da hermenêutica existencial de Heidegger pudesse levar a uma epistemologia alternativa, diametralmente oposta às epistemologias fundacionistas clássicas. Nessa instigante quiçá inusitada proposta de Westphal, não é claro quão promissora poderia ser essa proposta, justamente porque o compromisso de Heidegger sempre foi com a ontologia e não com a epistemologia.

Richard Rorty ${ }^{36}$, filósofo em constante diálogo com as diversas tradições filosóficas, também sustenta uma concepção muito próxima de Westphal, mostrando que uma empreitada investigativa nessa direção não é descabida. Rorty rejeita a visão representacional do conhecimento e a verdade como correspondência, consequentemente negando as aspirações fundacionistas da filosofia para a epistemologia. O caminho alternativo, para ele, está em sua reformulação do pragmatismo de William James e na hermenêutica filosófica. Embora sua argumentação aproxime a tradição epistemológica da tradição fenomenológica, essa posição radicaliza o problema da fundamentação ao ponto do abandono de uma busca por uma teoria do conhecimento. Westphal não vai tão longe quanto Rorty ao ponto de pôr fora a possibilidade da epistemologia; pelo contrário, ele pretende apontar uma saída para os impasses contemporâneos mostrando que a hermenêutica poderia fornecer uma teoria de extração coerentista em epistemologia. Dentro dessa perspectiva, pretendemos a seguir expor uma teoria coerentista da epistemologia, a fim de compreendermos me-

\footnotetext{
34 Interessante notar que no último decênio houve um interesse acentuado na posição de Hegel por parte do que se convencionou chamar de filosofia analítica. Veja-se para isso o artigo de Robert Brandom, "Hegel e a filosofia analítica", publicado na revista Veritas, Porto Alegre, 2011, v.56, n.1, p.78-94.

35 WESTPHAL, M. A hermenêutica enquanto epistemologia. In: GRECO, John; SOSA, Ernest. (org.). Compêndio de epistemologia. São Paulo: Loyola, 2008. p. 645-676.

${ }^{36}$ RORTY, Richard. A filosofia e o espelho da natureza. Rio de Janeiro: Relume-Dumará, 1994.
} 
Ihor como esses campos filosóficos podem se aproximar. Na última parte desse artigo, avaliaremos algumas questões que podem ser levantadas à luz da posição da hermenêutica heideggeriana.

\section{III - A epistemologia coerentista de Keith Lehrer}

Não existem muitos defensores em epistemologia analítica da posição coerentista. Pode-se indicar ao menos três filósofos que propõem abordagens epistemológicas coerentistas mais sistemáticas. Wilfrid Sellars, Laurence Bonjour e Keith Lehrer. Sellars tem se dedicado principalmente com filosofia da mente. Suas teses epistemológicas são desenvolvidas somente na medida em que precisa delas para sustentar as teses sobre a mente e a consciência. Embora fosse interessante avaliarmos sua posição, o espaço que aqui dispomos não comporta tal exposição. Seria preciso um trabalho específico articulando as teses epistemológicas espalhadas em sua obra, bem como pesando a maneira como elas são sustentadas no quadro da filosofia da mente. Bonjour, um dos primeiros proponentes de uma explícita teoria coerentista em epistemologia, propõe um coerentismo internalista. Porém, como demonstrado por diversos filósofos ${ }^{37}$, sua teoria parece falhar ao exigir um "imput" exterior observacional que teria suporte em uma metajustificação de caráter fundacional ${ }^{38}$. Lehrer parte da teoria de Bonjour, mas procura aprofundá-la e livrá-la das inconsistências indesejáveis surgidas em Bonjour ${ }^{39}$ tal como uma infiltração fundacionista.

\footnotetext{
37 Remeto aqui aos filósofos brasileiros Christiane Fianco e Júlio César Burdzinski. Suas teses doutorais versam sobre o coerentismo. Em Fianco, é destacado e analisado minuciosamente a posição de Bonjour.

38 FIANCO, Cristiane. O coerentismo de Bonjour: uma leitura fundacional. 2011. Tese (Doutorado em Filosofia) - Programa de Pós-Graduação em Filosofia, Universidade Federal do Rio Grande do Norte, Natal, 2011.

39 BURDZINSKI, Júlio César. Coerência e justificação epistêmica: um estudo das teorias de Laurence Bonjour e Keith Lehrer. 2004. Tese (Doutorado em Filosofia) - Faculdade de Filosofia e Ciências Humanas, Pontifícia Universidade Católica do Rio Grande do Sul, Porto Alegre, 2004, p.78-81.
} 
Entretanto, qual o problema com o fundacionismo, afinal? Espontaneamente, usamos nossas impressões sensoriais para cumprir um importante papel doxástico. No cotidiano mais ordinário, não parece ser um problema justificar uma crença apelando para os dados dos sentidos. Por exemplo, se alguém pergunta como sei que o banco abre às 10 horas, posso responder que vi na grade de horários, afixada na porta do estabelecimento, onde havia boa iluminação no local e a tabela era atualizada. Isso equivale a dizer: "eu vi em condições adequadas para saber que $p$ é o caso" e serviria perfeitamente como justificação no cotidiano; isto é, a evidência ' $e$ ' transfere justificação para a crença ' $p$ '. Contudo, sabemos também que nossos sentidos falham e uma teoria do conhecimento que pretenda fundar a justificação nas impressões sensoriais terá que responder, entre outras coisas, como que elas podem justificar uma crença - como que ocorre o erro? Não havendo resposta certa ou infalível, é mais adequado nesse caso dizer que as impressões sensoriais podem causar crenças, mas não justificar crenças. Equivale dizer: não há crenças de um tipo especial que justifique outras crenças. Claro que aqueles que defendem o fundacionismo darão boas explicações de por que a crença ' $b$ ' é básica e não necessita ser justificada. Todavia, se eles dispõem de uma explicação de porque ' $b$ ' é básica, isso já não é uma justificação? Parece que se reabre o problema do regresso ao infinito. A justificação proposicional do fundacionismo, como apresentada sumariamente acima, acaba por impedir que aquelas crenças, que devem ser básicas para justificar o sistema de crenças de $S$, não sejam arbitrárias.

Keith Lehrer ${ }^{40}$ propõe que talvez possamos justificar, sim, uma crença com outras crenças. Ele não apela para que uma ou várias crenças sejam básicas ou autoevidentes e nem aceita a circularidade viciosa. Ele sugere que uma proposição é justificada quando faz parte de um conjunto de proposições "coerentes" - daí provém o cognato de coerentismo. Ainda

40 LEHRER, Keith. Theory of knowledge. 2nd ed. Boulder: Westview, 2000. 
assim, fica a dúvida: O que é uma justificação coerentista? Lehrer ${ }^{41}$ diz que existem vários tipos de coerentismos, mesmo considerando somente os de cunho epistemológico. Existem quatro tipos ao menos, segundo ele, de coerentismo epistemológico: (1) fraco, (2) forte, (3) positivo e (4) negativo. O tipo (1) fraco afirma que "o modo pela qual uma crença está em coerência com nosso sistema de crenças de fundo é um determinante da justificação"; o outro tipo (2) afirma que "justificação é somente uma questão de como uma crença entra em coerência com um sistema de crenças". O outro tipo, positivo (3), afirma que "se uma crença é coerente com o sistema de crenças de fundo, então esta crença está justificada”; enquanto o tipo negativo (4) afirma "se uma crença falhar em entrar em coerência com um sistema de crenças de fundo, então a crença não estará justificada". Lehrer defenderá uma teoria coerentista do tipo fraco, como se pode verificar com sua afirmação de que "nenhuma relação entre enunciados é o bastante para a justificação completa. Em adição às relações entre enunciados, algo mais deve ser adicionado como ingrediente da justificação"42.

Sabemos até agora somente que o coerentismo de Lehrer entende que uma crença, para estar justificada precisa ter uma relação com outras crenças de tal modo que elas não se cancelem, não façam uma circularidade viciosa e mantenham uma ordem coesa. Que modo é esse? Como essa definição leva a epistemizar a crença? Essas são objeções feitas por outros autores à Lehrer, de que a "coerência" não está conectada com a verdade, sendo a ocorrência da verdade apenas uma questão de sorte. Lehrer responde:

Teorias da coerência abraçam o falibilismo, com certeza, mas isso não sustenta a oposição. Coerência é conexão com a verdade por princípios de aceitação justificada que explicam

\footnotetext{
${ }^{41}$ LEHRER, Keith. Coherentism. In: DANCY, Jonathan; SOSA, Ernest; STEUP, Matthias (ed.). A Companion to epistemology. 2nd ed. Oxford: Blackwell Publishers, 2010. p. 278-281.

42 LEHRER, Keith. Theory of knowledge. 2nd ed. Boulder: Westview, 2000, p. 108.
} 
a relação entre coerência e verdade. Coerência é conexão com a verdade por princípio explicativo, e não apenas sorte. ${ }^{43}$

Lehrer antes sugeria, na mesma passagem do artigo, que "algo mais deve ser adicionado como ingrediente da justificação". Este algo é "o modo pelo qual uma crença está em coerência com nosso sistema de crenças de fundo (...) [determinando a justificação]". Esse modo, esse elemento, ele o diz agora: é aceitação justificada; “Coerência é conexão com a verdade por princípios de aceitação justificada"44. Assim, ele tenta uma definição de 'conhecimento' que cumpra a definição clássica de "crença verdadeira justificada" agregando um quarto elemento para não ser pego nos casos tipo-gettier: "S sabe que p se e somente se (1) S aceita p, (2) é verdade que $p,(3)$ S está completamente justificado em aceitar que $p, e(4) S$ não é derrotado (defeated) por nenhum enunciado falso"45. Formalizando a definição coerentista de conhecimento (DCC):

$(\mathrm{DCC}) \quad(\forall \mathrm{s}) \mathrm{Ksp} \leftrightarrow\left[\mathrm{Asp}^{\wedge} \mathrm{Tp}^{\wedge} \mathrm{Jsp}^{\wedge} \sim(\exists \mathrm{u})(\mathrm{Dsup})\right]$

Onde 's' é um sujeito qualquer, 'p' é uma proposição sobre o mundo, 'u' é uma proposição falsa sobre o mundo que pode fazer s descrer (unbelief) de $p$, 'K' é "sabe que", 'A' é "aceita a crença de que", 'T' é "verdade", 'J' é "justificado em aceitar crer que" e 'D' é "derrotado por" (defeater).

É possível notar em um primeiro olhar duas coisas na DCC: que não aparece o conceito de "coerência" e o conceito de "aceitação" possui grande relevância para compreensão de sua definição de conhecimento; principalmente porque ele ocupa o lugar onde colocaríamos a "crença". Ao invés dele dizer "S crê que p", ele diz "S aceita a crença de que p". Assim,

43 LEHRER, Keith. Coherence and the truth connection. Erkenntnis, [s. l.], v. 63, n. 3, p. 413$423,2005$.

44 LEHRER, Keith. Coherence and the truth connection. Erkenntnis, [s. l.], v. 63, n. 3, p. 413$423,2005$.

45 LEHRER, Keith. Theory of knowledge. 2nd ed. Boulder: Westview, 2000, p. 147. 
cabe seguir o autor para ver como ele expõe o conceito de "aceitação", i.e., em que consiste a "aceitação":

[Aceitação] consiste em aceitar algo com o propósito de obter a verdade e evitar o erro. Com respeito àquilo que alguém aceita, mais precisamente, o propósito é aceitar que $p$ se e somente se $p .{ }^{46}$

O autor quer fazer uma distinção entre aceitar crer que $p$ e crer que $p$. Conforme o que ele diz, a aceitação é um tipo especial de crença; é aquele tipo de crença que se tem com vistas de se obter a verdade e afastar o que é falso. Mas por que seria assim? E ele nos diz, na mesma passagem:

[Ora,] algumas vezes nós acreditaríamos em coisas as quais não aceitaríamos considerando-se esse objetivo epistêmico. Podemos acreditar antes em algo para atingirmos a felicidade que a verdade (...). É a aceitação de algo tendo em vista a busca da verdade que é condição requerida para o conhecimento. ${ }^{47}$

Se a "aceitação" cumpre um papel importante na epistemização da crença verdadeira, como que $S$ decide o que deve ou não ser aceito? Lehrer dá uma resposta que faz aparecer o princípio coerentista por ele defendido: a decisão por aceitar ou não uma crença se dá na confrontação com outras crenças já aceitas por $S$. Todavia, isso pode parecer completamente arbitrário e pior do que aceitar o fundacionismo com base na experiência sensorial. Se podemos nos enganar sobre o mundo externo, com razão também nos enganamos sobre nossos estados mentais - aliás, por que não aceitar os dados percebidos do mundo, então? Segundo o

\footnotetext{
46 LEHRER, Keith. Theory of knowledge. 2nd ed. Boulder: Westview, 2000, p. 11.

47 LEHRER, Keith. Theory of knowledge. 2nd ed. Boulder: Westview, 2000, p. 11. Uma formulação similar ocorre nas pp. 32 a 38. Interessante comparar, caso o leitor tenha interesse em aprofundar.
} 
autor, porque não temos esta alternativa de reivindicarmos a experiência, as impressões dos sentidos, como acesso ao mundo de maneira imediata ${ }^{48}$. Prossegue ele na mesma passagem do livro:

\begin{abstract}
Nossos sentidos podem nos dar base para alguma concepção ou crença sobre o que ocorre conosco em nossa vizinhança sensorial. Como podemos decidir, entretanto, se o que é sugerido a nós pelos sentidos é verdadeiro, ao invés de falso e ilusório? É o que tínhamos já aceito em vistas da verdade. É o nosso sistema de fundo (background system) de informações aceitas. ${ }^{49}$
\end{abstract}

Isso, sugere o autor, que o modo pelo qual valoramos nossas crenças em relação à verdade está articulada com aceitação destas crenças dentro do conjunto de todas nossas crenças, sejam elas oriundas dos sentidos, memória, raciocínio, testemunho etc. O valor de verdade de todas nossas crenças está baseado em nosso sistema de aceitação (acceptance), e esse sistema contém nossa concepção de mundo e acesso a ele. Mais ainda afirma o autor, que "não há saída do círculo daquilo que aceitamos" ${ }^{\circ}$. Nesse ponto, podemos perceber que Lehrer está criando uma maneira de prescindir de uma base evidencial inconteste, afastando-se do fundacionismo ou de que sua teoria transforme-se somente em um tipo de fundacionismo moderado, aproximando-se arriscadamente da circularidade viciosa. Até aqui ainda não está completamente claro de que modo articula-se cada um dos elementos da DCC para epistemizar a crença; mas, já vemos que sua ideia de "sistema de aceitação" cumpre um papel importante.

Há outra coisa notável que podemos perceber de diferença entre o coerentismo de Lehrer e as teorias fundacionistas. No fundacionismo, a justificação ocorre através de uma proposição, digamos r, que transfere

\footnotetext{
48 LEHRER, Keith. Theory of knowledge. 2nd ed. Boulder: Westview, 2000, p. 112.

49 LEHRER, Keith. Theory of knowledge. 2nd ed. Boulder: Westview, 2000, p. 112.

50 LEHRER, Keith. Theory of knowledge. 2nd ed. Boulder: Westview, 2000, p. 113.
} 
justificação para outra proposição, digamos p. No coerentismo (e também no infinitismo) ${ }^{51}$, a justificação emerge a partir de um conjunto de proposições. Cada proposição é justificada em termos de sua pertença ao conjunto de proposições que, no caso do coerentismo, deve manter uma relação estável de sistematicidade, ou melhor, de coerência entre as proposições. As proposições passam a ter justificação ao fazerem parte do sistema. Nesse sentido, pode-se ver o elemento de circularidade novamente, embora também se possa dizer que a propriedade que torna uma proposição justificada é constituir-se em um todo fundamental.

Mas vejamos como funciona a ideia de Lehrer de "sistema de aceitação". O Sistema de Aceitação (doravante SA) de S é um sistema de crenças diferente de outros sistemas de crenças de $S$, pois o SA de $S$ é aquele sistema de crenças de $S$ com vistas a manter o verdadeiro e evitar a falsidade ${ }^{52}$. A crença $p$ estará coerente com o SA de $S$, no tempo $t$, se e somente se é mais razoável para $S$ aceitar $p$ que qualquer crença competidora $u$, tendo como base o SA de $S$ em $t^{53}$. A inclusão do tempo no SA é devido a Lehrer entender que um SA pode se manter em constante transformação, com a entrada de novas crenças no sistema. Isso também significa o entendimento de que o SA possui uma evolução que deve ocorrer não só com a entrada de novas crenças, mas com a saída delas.

Esse processo evolutivo do SA ocorre como uma competição de crenças para entrar no SA de $S$ em um determinado momento $t$. (1) Uma crença $c$ entra em competição com uma crença $p$ para $S$, em seu $S A$, se e somente se for menos razoável para $S$ crer em $p$ caso $c$ seja considerada verdadeira que se $S$ assumisse $c$ como falsa. (2) A crença $p$ somente vence a competição para $S$ se a razoabilidade de crer em $p$ é maior que crer em

51 FLORES, Tito Alencar. Racionalidade epistêmica e o processo de justificação. 2004. Tese (Doutorado em Filosofia) - Faculdade de Filosofia e Ciências Humanas, Pontifícia Universidade Católica do Rio Grande do Sul, Porto Alegre, 2004.

52 LEHRER, Keith. Theory of knowledge. 2nd ed. Boulder: Westview, 2000, p. 117.

53 LEHRER, Keith. Theory of knowledge. 2nd ed. Boulder: Westview, 2000, p. 117. 
$c$ mesmo que $c$ fosse o caso ${ }^{54}$. Dito de outro modo, no caso (1) $S$ crê em $p$ e não vê nenhuma razão para descrer de $p$. Entretanto, com o aparecimento da crença $c, S$ passa a avaliá-la frente ao seu SA e pondera: se $c$ for verdadeira, então é menos razoável aceitar $p$; todavia, se $c$ for falsa, aceitar $p$ é o mais razoável a fazer. No caso (2), $p$ vence se e somente se crer em $p$ é mais razoável, mesmo se $c$ for verdadeira.

Há um terceiro caso que Lehrer aponta, o da neutralização na competição. Uma crença $n$ é neutralizadora quando, em conjunção $\operatorname{com} c$, retira o caráter competidor de $c$ para com $p$ no SA de $S$. Dito de outro modo, assim como no caso (1), S crê em $p$ e não vê nenhuma razão para descrer de $p$; entretanto, com o aparecimento da crença $c$, $S$ passa a avaliá-la frente ao seu SA e pondera: se $c$ for verdadeira então é menos razoável aceitar $p$; todavia, se $c$ for falsa, aceitar $p$ é o mais razoável a fazer. Mas, enquanto $S$ pondera a aceitação de $c$ em seu sistema de crenças aceitáveis, surge uma crença $n$ que leva $S$ perceber que se $n$ estiver junto com a crença competidora $c$, não há dúvidas quanto à razoabilidade em aceitar $p^{55}$.

Com esses esclarecimentos, podemos chegar a uma definição compreensível do que seja uma justificação coerentista (neste caso, na teoria de Lehrer) e esclarecer o termo 's $s$ ' ( $S$ está justificado em crer que $p$ ) da definição formal em $D C C$. Vejamos a definição: $S$ está justificado em aceitar que $p$ (Asp), no instante $t$, com base no sistema de crenças $X$ de $S$ em $t$ se e somente se $p$ é coerente com $X$ de $S$ em $t$, e ainda se e somente se todos os competidores de $p$ são vencidos ou neutralizados para $S$ em $X$ em $t^{56}$. Dito de outro modo, e em resumo do que foi explicitado até aqui: $S$ sabe que $p$, e sendo $p$ verdade, quando $S$ crê de forma responsável em $p$, ou seja, aceita crer em $p$ buscando a verdade e querendo evitar o erro; i.e., sendo $p$ o caso, $S$ sabe que $p$ quando $S$ aceita que $p$ e $S$ está justificado em crer que $p$ com base em seu sistema de crenças que busca a verdade,

\footnotetext{
54 LEHRER, Keith. Theory of knowledge. 2nd ed. Boulder: Westview, 2000, p. 118.

55 LEHRER, Keith. Theory of knowledge. 2nd ed. Boulder: Westview, 2000, p. 148.

${ }_{56}$ LEHRER, Keith. Theory of knowledge. 2nd ed. Boulder: Westview, 2000, p.148.
} 
além de que não há sequer uma crença c ou n que esteja competindo com $p$ para que $S$ tenha dúvidas da razoabilidade em aceitar $p$.

Lehrer ainda refinará mais sua teoria para distinguir outras sutilezas. De toda forma, com a definição alcançada até aqui, já é possível termos uma ideia de como o coerentismo aborda a circularidade e o problema do regresso; além de podermos apontar uma objeção que Peter Klein ${ }^{57}$ faz ao coerentismo. A objeção de por que deveríamos aceitar um sistema coerente ao invés de um incoerente? Parece estranho em um primeiro instante perguntar se incoerência não seria melhor, mas essa questão cumpre uma função na argumentação de Klein. Se o coerentista responder que, pelo fato de proposições relacionarem-se de modo coerente, elas possuem mais probabilidade de serem verdadeiras, então Klein perguntará se essa proposição "proposições que se relacionam de modo coerente possuem mais probabilidade de serem verdadeiras" está incluída no conjunto coerente inicial ou não. Vemos aqui a armadilha argumentativa de Klein: se a resposta for "sim", então o sistema é viciosamente circular. Se for "não", a resposta recai no regresso ao infinito por ser uma nova proposição que não estava no sistema, mas que o justifica.

Tito Flores ${ }^{58}$ acrescenta aí que é justamente na tentativa do coerentista em afugentar a má circularidade que ele pode cair no fundacionismo, lançando mão de um princípio que não está no seu sistema, mas que o fundamenta. O problema do coerentista não está na "ideia geral que regula a justificação epistêmica"; mas, da maneira como o conjunto de proposições está arranjado, implica a circularidade - esse é sempre o risco da teoria.

O coerentista tentará sempre defender uma forma de relação entre as proposições que seja de tal modo complexa, que ele possa explicar como é possível o conjunto de proposições justificar uma nova proposição que

\footnotetext{
57 KLEIN, Peter D. Infinitism's take on justification, knowledge, certainty and skepticism. Veritas, Porto Alegre, v. 50, n. 4, p. 153-172, 2005.

58 FLORES, Tito Alencar. Racionalidade epistêmica e o processo de justificação. 2004. Tese (Doutorado em Filosofia) - Faculdade de Filosofia e Ciências Humanas, Pontifícia Universidade Católica do Rio Grande do Sul, Porto Alegre, 2004.
} 
se estabeleça em seu sistema. Digo "sempre" porque nenhum filósofo respeitável sustentará uma tese simplista do coerentismo, do tipo $S$ sabe que $p$, e está justificado porque $r$, que se justifica por $v$ e que, finalmente, é razoável porque $p$. O coerentista relevante em geral apresentará uma imagem como metáfora a sua teoria (que pode ser o barco de Neurath ou, como atualmente é mais corriqueiro, a rede ${ }^{59}$ ). Com essa metáfora, o coerentista dará a entender que não é uma relação de proposição a proposição que justifica uma crença, mas a forma assumida pelo sistema como um todo. Em outros termos, o conjunto todo deve possuir uma forma tal que ofereça sustentação para uma nova crença (um novo nó na rede, como sugerem metaforicamente alguns contemporâneos); embora, ao final de toda explanação do coerentista, possamos dizer "Entendi, tudo certo; porém, resumindo, $p$ colabora na sustentação de $p$, não é?". A resposta, se for sincera, terá de ser "sim".

De toda forma, para encerrar este tópico, o coerentista terá que lidar com esse elemento de circularidade de modo inclusivo, aceitando-o, porque de outro modo ele retirará o caráter propriamente coerentista ou sistemático de sua teoria e cairá ou em um fundacionismo ou terá que se socorrer no infinitismo. Seja qual for a estratégia adotada pelo coerentista, ela deve dar uma explicação de como essa "rede" sustenta-se ao ponto de pensarmos que não pode ser de outra maneira a forma como uma crença verdadeira se epistemiza.

\footnotetext{
59 O Barco de Neurath faz referência a alegoria apresentada em mais de um lugar na obra do filósofo Otto Neurath de como nosso conhecimento é construído. Segundo ele, nossas teorias e conhecimento são estruturados tal como um barco em alto mar que nunca pode encontrar uma doca seca a fim de realizar manutenção das tábuas que o sustentam à superfície. Temos de ajustar o conjunto coeso das tábuas do barco, estancar vazamentos e reforma-lo somente com o material que já dispomos no próprio barco e sem poder desmontá-lo, senão afundaríamos. Uma das versões de sua alegoria pode ser conferida em NEURATH, M. Protocol statements. In: NEURATH, M. Philosophical papers 1913-1946. Dordrecht: Reidel, 1983, p. 92. A "rede" referida aqui é a metáfora de que nossas proposições se relacionam tal como os nós em uma rede qualquer, que bem pode ser a imagem da rede de pesca como da rede de computadores mundial, i.e., a internet.
} 


\section{IV - Hermenêutica como epistemologia}

Como entender essa articulação entre hermenêutica existencial ou filosófica como epistemologia tal como Merold Westphal cogitou ser possível? A epistemologia contemporânea tem uma maneira própria de abordar questões, um método que de forma ampla tem-se chamado de "analítico". Método entendido como um caminho, é claro; não como um conjunto de procedimentos bem definidos que podem ser aplicados indistintamente por alguém que deseje investigar um objeto qualquer. Talvez método nesse sentido forte seja algo distante da filosofia, ainda que partilhemos ora ou outra de procedimentos mais ou menos ordenados em nossas pesquisas. Diferente das ciências, no sentido de um empreendimento precipuamente não filosófico, na filosofia não se pode cultivar a ilusão de pensar que as questões metodológicas são obscuras, porque o método já está sempre intimamente articulado com o objeto que se pretende investigar ${ }^{60}$. Pensarmos que é no confronto com o objeto filosófico que se vai escolher o método é um equívoco, pois o método impõe o âmbito e a amplitude da questão filosófica. Isso significa que o procedimento metódico que orienta a razão é uma escolha do filósofo que no seu entender é a maneira mais produtiva de dar resposta, ou chegar, a um problema filosófico ${ }^{61}$.

A maneira de proceder que se adotou para expor sucintamente a teoria de Lehrer é típica da tradição epistemológica contemporânea, e não há nada de errado com ela em si. O que Westphal viu na hermenêutica foi uma maneira de proceder com as questões epistemológicas. Essa maneira de proceder da hermenêutica heideggeriana não parte de uma racionalidade que trata de objetos. Parte de uma condição anterior ao discurso proposicional. A pergunta que se põe com relação ao conhecimento nessa maneira de proceder é das condições de possibilidade do conhecimento. $\mathrm{Na}$

\footnotetext{
6o STEIN, Ernildo. Questão do método em filosofia: um estudo do modelo heideggeriano. Porto Alegre: Movimento, 1983, 12.

${ }_{61}$ STEIN, Ernildo. Questão do método em filosofia: um estudo do modelo heideggeriano. Porto Alegre: Movimento, 1983. p. 14-15.
} 
epistemologia contemporânea, trabalha-se com teoria do conhecimento sem referir-se à ontologia. $O$ que se entende é que, em princípio, qualquer tese ontológica poderia se encaixar em uma epistemologia robusta. A posição heideggeriana é oposta a essa visão por entender que não se evita comprometimentos ontológicos somente por se recusar em tratar da dimensão metafísica de nossas formulações em outras áreas do saber. Os compromissos ontológicos, por constrangerem nossas teses derivadas, devem ser revisados em nossa reflexão, a fim de não cairmos em aporias.

A possibilidade de pensarmos, e por extensão pensarmos a epistemologia, é dada por uma condição que emerge de uma relação fundamental e anterior a todo pensar de objetos, do pensar proposicional ${ }^{62}$. Essa condição é uma condição do próprio ser que somos nós mesmos, designado por Heidegger como ser-aí (Dasein), o qual é entendido fundamentalmente como ser-no-mundo (in-der-Welt-sein). É porque o ser-aí se dá como ser-no-mundo enquanto cuidado (Sorge) ${ }^{63}$, e o sentido de cuidado é dado como temporalidade (Zeitlichkeit) ${ }^{64}$, e a temporalidade é a condição para haver sentidos ${ }^{65}$, significados, é que o sentido proposicional tratado na epistemologia encontra-se em uma posição derivada ${ }^{66}$. O filósofo Ernildo Stein trata minuciosamente desse tema em Pensar é pensar a diferença ${ }^{67}$ formulando em síntese a posição heideggeriana nesse assunto como sendo a de "um transcendental não clássico". Não clássico porque, ao pôr o fundamento no modo existencial, Heidegger assume que não há uma base primeira; não há "alicerces", para pensar em uma metáfora cartesiana. Para Stein,

\footnotetext{
62 HEIDEGGER, M. Ser e tempo. Tradução: Fausto Castilho. Campinas: Unicamp, 2012, p. 407-415.

63 HEIDEGGER, M. Ser e tempo. Tradução: Fausto Castilho. Campinas: Unicamp, 2012, p. 535.

64 HEIDEGGER, M. Ser e tempo. Tradução: Fausto Castilho. Campinas: Unicamp, 2012, p. 829-831.

65 HEIDEGGER, M. Ser e tempo. Tradução: Fausto Castilho. Campinas: Unicamp, 2012, p. 913 , 923, 947-951.

66 HEIDEGGER, M. Ser e tempo. Tradução: Fausto Castilho. Campinas: Unicamp, 2012, p. 971.

${ }_{67}$ STEIN, Ernildo. Pensar é pensar a diferença: filosofia e conhecimento empírico. 2. ed. Ijuí: Unijuí, 2006.
} 
Heidegger, ao operar uma fundamentação na própria existência, aponta para onde estarão enraizadas as teorias e justificações em epistemologia ${ }^{68}$.

Seibt $^{69}$, em concordância com Stein, afirma que "é experiência da experiência, mas não no sentido de algo que estivesse além da própria experiência", porque em "toda experiência há uma diferença (...) que (...) nos dá a proporção da experiência, e introduz sentido na experiência"70. Esse sentido dado pelo modo existencial organiza aquilo que irrefletidamente chegamos a entender como campo da experiência, como a dimensão empírica. Essa dimensão empírica, onde nossas experiências ocorrem, possui um alcance limitado pela temporalidade, é o horizonte do ser-no-mundo. Dentro desse horizonte emerge uma rede de sentidos produzida pela existência e é dentro dessa rede que, eventualmente, podemos pensar, por exemplo, em relações de causa e efeito empíricos ${ }^{71}$. Portanto, o conhecimento nesse quadro existencial oferecido por Heidegger é antes de mais nada uma pré-compreensão do mundo. É nesse sentido que se fala de uma "hermenêutica filosófica" ou existencial, como uma interpretação, uma compreensão prévia que se dá ao modo de nossa própria existência.

Nesse nível ontológico apresentado por Heidegger, não há nada como uma representação de objetos do mundo por um sujeito conhecedor. O "sujeito conhecedor", antes de se compreender como tal, já apreendeu o mundo em sua existência. Por isso Heidegger diz que já sempre compreendemos $\operatorname{ser}^{72}$, que somos já sempre abertos ao mundo ${ }^{73}$ e concebe o ser humano como ser-aí que somente tem sentido pleno como ser-no-mundo. Não há

\footnotetext{
68 STEIN, Ernildo. Pensar é pensar a diferença: filosofia e conhecimento empírico. 2. ed. ljuí: Unijuí, 2006, p. 94.

69 SEIBT, Cezar Luís. A hermenêutica heideggeriana e a questão do conhecimento. Conjectura: Filosofia e Educação, Caxias do Sul, v. 21, n. 1, p. 188-214, jan./abr. 2016, p. 194.

70 STEIN, Ernildo. Pensar é pensar a diferença: filosofia e conhecimento empírico. 2. ed. Ijuí: Unijuí, 2006, p. 103.

71 STEIN, Ernildo. Pensar é pensar a diferença: filosofia e conhecimento empírico. 2. ed. ljuí: Unijuí, 2006, p. 118.

72 HEIDEGGER, M. Ser e tempo. Tradução: Fausto Castilho. Campinas: Unicamp, 2012, p. 59.

73 HEIDEGGER, M. Ser e tempo. Tradução: Fausto Castilho. Campinas: Unicamp, 2012, p. 515-533.
} 
um vazio de sentido ou um fundo a ser descoberto por trás da existência, nossa abertura ao mundo é o mais recuado que se pode ir pela via do pensar. Nossa abertura (Erschlossenheit) é a maneira pela qual nos constituímos ${ }^{74}$ e por isso já temos sempre conhecimento do mundo, atravessado também por várias dimensões, estas linguísticas e culturais. A abertura do ser-aí é uma dimensão de ser-no-mundo que possibilita as teorizações de qualquer tipo, porque ela é horizonte originário onde o sentido se dá.

Uma teoria do conhecimento nos moldes contemporâneos dentro da proposta hermenêutica, fundamentalmente heideggeriana, significa partir de uma compreensão mais originária que o entendimento proposicional, partir desse âmbito do ser-aí enquanto ser-no-mundo. É pensar no conhecimento como um fenômeno que se dá enquanto modo do ser-aí. A possibilidade de sentido dos objetos está circunscrita a um horizonte prévio que organiza a experiência em termos de compreensão. A manifestação dos entes enquanto entes aparece dentro desse horizonte de sentido do ser-no-mundo. Todos esses pontos trazidos nos últimos três parágrafos são os elementos centrais da filosofia de Heidegger concernente à autocompreensão do ser humano como um ser que compreende mundo e que, antes de qualquer teoria, já sabe e conhece o mundo. Como entender esses elementos e "traduzir" em algum nível para articular uma aproximação com uma perspectiva epistemológica, da maneira como Dancy ou Westphal viram? Pelas dimensões e limites desse trabalho, como já dissemos no início, tentamos seguir certos apontamentos a um caminho possível de ser explorado.

O que um epistemólogo precisa entender para seguir na direção de Westphal são os problemas que Heidegger criticou na maneira de filosofar tradicional. Ernildo Stein resume bem a crítica de Heidegger afirmando que há algo anterior à própria evidência apresentada em qualquer teoria; há algo anterior mesmo antes do ponto de partida postulado por alguma

74 HEIDEGGER, M. Ser e tempo. Tradução: Fausto Castilho. Campinas: Unicamp, 2012, p. 909-913. 
teoria do conhecimento, isto é: uma anterioridade às teses de subjetividades fundantes ${ }^{75}$. Stein afirma nessa passagem que esse "algo anterior" é uma "evidência operando na situação de ser-no-mundo". Essas teorias do conhecimento acabam por deixar oculto o que as torna possíveis, escapando a elas parte daquilo que tentam explicar. Essas teorias tentam dar conta de explicar como que a explanação acerca da experiência do sujeito (i.e., a teoria do conhecimento) pode revelar a verdade dessa experiência. Ao fazê-lo, excluem a própria experiência que produziu um conhecer ou a desnaturam de sua dimensão existencial. "Há algo a mais no fenômeno do conhecimento do que aquilo que é apresentado pelas teorias do conhecimento. "Algo que as torna possíveis, mas que mantém a si mesmo no ocultamento", afirma Seibt ${ }^{76}$ em concordância com Stein.

A crítica heideggeriana sendo aceita, teríamos de abandonar a empresa epistemológica? Não nos parece que essa é a implicação, embora parte do que se faz sob esse nome possa sofrer uma alteração profunda. Mantendo o que poderia ser salvo da destruktion heideggeriana, o epistemólogo deveria proceder como? De que maneira deveria ele tratar a dimensão proposicional em concordância com a hermenêutica fenomenológica77? Um caminho possível para como deveria proceder o epistemólogo é avaliar que teorias ou teses epistemológicas são imediatamente derrotadas (defeated) frente à hermenêutica de Heidegger. O fundacionismo é rejeitado de imediato por esse critério. Praticamente todo o fundacionismo possui comprometimentos ontológicos que estão inscritos de um jeito ou de outro naquilo que Heidegger chamou de "esquecimento do ser". A destruição da metafísica, como chamou o filósofo alemão, foi sua investida contra a metafísica da

\footnotetext{
75 STEIN, Ernildo. Seis estudos sobre ser e tempo. 4. ed. Petrópolis: Vozes, 2008, p. 21-24.

76 SEIBT, Cezar Luís. A hermenêutica heideggeriana e a questão do conhecimento. Conjectura: Filosofia e Educação, Caxias do Sul, v. 21, n. 1, p. 188-214, jan./abr. 2016, p. 196.

77 Ao menos quatro adjetivos já foram usados pelos comentadores à hermenêutica desenvolvida por Heidegger e, posteriormente, Gadamer: filosófica, existencial, da facticidade e fenomenológica. Em sua obra inteira, Stein já empregou todos esses qualificadores para o termo 'hermenêutica' quando nos contextos de uso similares aos aqui empregados.
} 
substância, os fundacionismos em metafísica e epistemologia, a procura de um fundamento ou garantia para a verdade e a realidade.

Toda teoria, ou o teorizar, é um comportamento, uma prática do ser-no-mundo dentro de seu horizonte de sentido. Qualquer tese epistemológica também terá que ser construída dentro dos limites temporais ao que o ser humano está lançado. O ser-aí compreende mundo dentro de um horizonte de sentido, como já dissemos de outro modo acima; logo, suas teorias serão sempre limitadas às experiências que ele próprio tem. Significa que não atingiremos teorias totais e finais da verdade ou do conhecimento porque o Dasein é um ser existencialmente finito. Para dizer de uma maneira não fenomenológica, qualquer teoria do conhecimento não poderá optar pelo fundacionismo e terá de incorporar seriamente algum tipo de falibilismo para se manter adequada à ontologia heideggeriana. O sujeito cognoscente não pode ser mais fundamento do conhecimento (afastando o idealismo), nem os objetos no mundo fornecem o critério de verdade ou adequação ao nosso modo teórico de se apropriar de nossas experiências. O sujeito não pode ser fundamento porque ele é entendido como ser-aí em um mundo: um modo de ser e não uma "coisa" onde se ancoram outras coisas ou proposições.

Não há um fundo objetivo onde enraizar as teorias, segundo Heidegger; então o epistemólogo terá possivelmente que abrir mão da garantia de crença verdadeira em sua teoria. O conhecimento é onticamente fundado no ser-no-mundo e terá de ser compreendido como apresentando características do modo de ser próprio do ser-no-mundo. Portanto, o epistemólogo teria de partir da relação prática do sujeito junto ao mundo e não, como sempre fez, partindo de um conjunto teórico que assumia o pressuposto de um ser-diante-do-mundo (sujeito cindido do objeto). Heidegger afasta de sua posição o modo teórico de racionalidade colocando-o como derivado do modo prático e fenomenológico. Essa descrição fenomenológica da nossa autocompreensão e "morada" no mundo, como resumido acima, é a hermenêutica da facticidade em alguns de seus momentos. Nossa pré-compreensão do mundo circunscrita na abertura como horizonte de sentido funciona de maneira circular: operando no 
mundo produzo um entendimento teórico que, de certa forma, afeta o horizonte de sentido em um movimento ininterrupto. As teorias serão sempre provisórias, nunca refletindo a natureza a qual deseja explicar de maneira completa. Quando uma teoria esclarece alguma experiência, altera o horizonte da compreensão e volta a obscurecer e encobrir sentidos. São esses momentos de encobrimento de sentido que permitem nossa pretensão às descrições totalizadoras da experiência e da existência ${ }^{78}$.

Diante dessas considerações e da exposição da teoria coerentista de Keith Lehrer, podemos perceber que é preciso assumir a posição fenomenológica para passar em revista a epistemologia e conseguirmos ver o que apontou Westphal. O teorema heideggeriano do círculo hermenêutico parece estar em sintonia com a maneira geral de como o coerentismo propõe que nossas crenças encontrem justificação no sistema doxástico. Uma sintonia conseguida não sem ter de reformular a noção de justificação para um modo falibilista. O sistema de crenças precisa estar em articulação coerente para se manter funcionando, remetendo a uma possível redescrição (ao modo fenomenológico) em termos temporais e da finitude. Como a rede de crenças coerentista não precisa de um fundamento a não ser sua coerência, aparentemente se presta bem para articulá-la como uma derivação do modo próprio do Dasein compreender mundo e o comportamento teórico descritos por Heidegger no §69 de Ser e Tempo. Uma articulação assim poderia resolver os problemas de circularidade viciosa apontada pelos críticos do coerentismo e nunca muito bem resolvidos no âmbito da epistemologia. Também se pode perceber que a epistemologia contemporânea tem estado preocupada em dar descrições teóricas que funcionem no mundo prático dos seres humanos. Esse elemento é um ponto favorável para se trabalhar com a hermenêutica da facticidade e a

\footnotetext{
78 Para um aprofundamento dessas relações entre a hermenêutica filosófica e o conhecimento, indicamos o artigo do filósofo Cezar Luis Seibt citado na bibliografia. Ele explora em boa parte da obra heideggeriana o tema do conhecimento. A leitura de Seibt está em profunda consonância com a interpretação que Ernildo Stein faz da obra heideggeriana, sendo seu principal referencial teórico nesse artigo.
} 
fenomenologia de modo geral. Westphal apontou uma direção que ainda está para ser construída e o coerentismo parece ser uma boa opção para encontrarmos uma epistemologia fenomenologicamente informada. Mas evidentemente há ainda muito trabalho a se fazer para desenvolver uma posição entre epistemologia analítica e hermenêutica filosófica.

\section{Referências}

ALSTON, William. P. Epistemic Justification: essays in the theory of knowledge. Ithaca: Cornell University Press, 1989.

ALSTON, William. P. Beyond justification: dimensions of epistemic evaluation. Ithaca: Cornell University Press, 2005. https://doi.org/10.1017/ s0012217300001876

AUDI, Robert. Belief, justification and knowledge. California: Wadsworth, 1988.

AUDI, Robert. The structure of justification. Cambridge: Cambridge Univ., 1993.

BONJOUR, Laurence. The structure of empirical knowledge. Cambridge: Harvard University Press, 1985.

BONJOUR, Laurence. Epistemology: classic problems and contemporary responses. Lanham: R \& L, 2002.

BURDZINSKI, Júlio César. Coerência e justificação epistêmica: um estudo das teorias de Laurence Bonjour e Keith Lehrer. 2004. Tese (Doutorado em Filosofia) - Faculdade de Filosofia e Ciências Humanas, Pontifícia Universidade Católica do Rio Grande do Sul, Porto Alegre, 2004. https://doi.org/10.24873/j. rpemd.2018.06.219

Brueckner, Anthony. Essays on skepticism. Oxford: Oxford University Press, 2010.

Dancy, Jonathan. Epistemologia contemporânea. Lisboa: Edições 70, 1985.

DANCY, Jonathan. Introducción a la epistemología contemporánea. 2. ed. Madrid: Tecnos, 2007.

DANCY, Jonathan; SOSA, Ernest; STEUP, Matthias (org.). Companion to epistemology. Oxford: Blackwell Publishers, 2010.

FIANCO, Cristiane. O coerentismo de Bonjour: uma leitura fundacional. 2011. Tese (Doutorado em Filosofia) - Programa de Pós-Graduação em Filosofia, 
Universidade Federal do Rio Grande do Norte, Natal, 2011. https://doi. org/10.7594/revbio.19.01.02

FLORES, Tito Alencar. Racionalidade epistêmica e o processo de justificação. 2004. Tese (Doutorado em Filosofia) - Faculdade de Filosofia e Ciências Humanas, Pontifícia Universidade Católica do Rio Grande do Sul, Porto Alegre, 2004. https://doi.org/10.24873/j.rpemd.2018.06.219

FLORES, Tito Alencar. The problem of the criterion, knowing that one knows and infinitism. Veritas, Porto Alegre, v. 50, n. 4, p. 109-128, 2005. https://doi. org/10.15448/1984-6746.2005.4.1818

FLORES, Tito Alencar. Epistemic levels, the problem of easy knowledge and skepticism. Veritas, Porto Alegre, v. 54, n. 2, p. 109-129, 2009. https://doi. org/10.15448/1984-6746.2009.2.6820

FOLEY, R. Conceptual diversity in epistemology. In: MOSER, Paul K. (Ed.). The Oxford handbook of epistemology. Oxford: Oxford University Press, 2002. p. 177-203. https://doi.org/10.1093/0195130057.003.0006

GADAMER, Hans-Georg. Verdade e método. 12. ed. Petrópolis: Vozes, 2012.

GETTIER, E. Is justified true belief knowledge? Analysis, [s. l.], n. 23, p. 121-123, 1963. https://doi.org/10.1093/analys/23.6.121

GOLDMAN, A. What is justified beilief? In: PAPPAS, G. (Ed.). Justification and knowledge: new studies in epistemology. Dordrecht: D. Reidel, 1979. p. 1-24. HEIDEGGER, M. Ser e Tempo. Tradução: Fausto Castilho. Campinas: Unicamp, 2012.

KLEIN, Peter D. Infinitism's take on justification, knowledge, certainty and skepticism. Veritas, Porto Alegre, v. 50, n. 4, p. 153-172, 2005. https://doi. org/10.15448/1984-6746.2005.4.1820

LEHRER, Keith. Theory of knowledge. 2nd ed. Boulder: Westview, 2000.

LEHRER, Keith. Coherence and the truth connection. Erkenntnis, [s. l.], v. 63, n. 3, p. 413-423, 2005. https://doi.org/10.1007/s10670-005-4003-3

LEHRER, Keith. Coherentism. In: DANCY, Jonathan; SOSA, Ernest; STEUP, Matthias (ed.). A Companion to epistemology. 2nd ed. Oxford: Blackwell Publishers, 2010. p. 278-281.

MOSER, Paul K. (ed.). The Oxford handbook of epistemology. Oxford: Oxford University Press, 2002. https://doi.org/10.1093/0195130057.001.0001 
NEURATH, M. Protocol statements. In: NEURATH, M. Philosophical papers 1913-1946. Dordrecht: Reidel, 1983. p. 91-99. https://doi.org/10.1007/97894-009-6995-7_7

POLLOCK, John L.; CRUZ, Joseph. Contemporary theories of knowledge. 2nd ed. Lanham: Rowman \& Littlefield, 1999.

RORTY, Richard. A filosofia e o espelho da natureza. Rio de Janeiro: RelumeDumará, 1994.

ROSS, David. Teoría de las ideas de Platón. 5. ed. Madrid: Catedra, 2001.

SEIBT, Cezar Luís. A hermenêutica heideggeriana e a questão do conhecimento. Conjectura: Filosofia e Educação, Caxias do Sul, v. 21, n. 1, p. 188-214, jan./abr. 2016.

STEIN, Ernildo. Pensar é pensar a diferença: filosofia e conhecimento empírico. 2. ed. ljuí: Unijuí, 2006.

STEIN, Ernildo. Questão do método em filosofia: um estudo do modelo heideggeriano. Porto Alegre: Movimento, 1983.

STEIN, Ernildo. Racionalidade e existência: o ambiente hermenêutico e as ciências humanas. 2. ed. ljuí: Unijuí, 2008.

STEIN, Ernildo. Seis estudos sobre ser e tempo. 4. ed. Petrópolis: Vozes, 2008.

SOSA, Ernildo. Epistemology: an anthology. Malden: Blackwell Publishers, 2000.

WESTPHAL, M. A hermenêutica enquanto epistemologia. In: GRECO, John; SOSA, Ernest. (org.). Compêndio de epistemologia. São Paulo: Loyola, 2008. p. 645-676. 